\title{
As ONGs e a responsabilidade governamental com a escola básica no Brasil
}

Elie Ghanem ${ }^{*}$

Resumo: Este texto apresenta alguns dos principais significados que as ONGs assumiram no Brasil, os quais as posicionam diante do desafio do direito à educação. Desafio que abarca, especialmente, a escolarização pública e a definição do campo público e do privado. Nos dois aspectos deste desafio, são descritas as perspectivas seguidas pelas ONGs: a paliativa, a inovadora, a de mudança ou a de pressão política. Em conclusão, afirma que a atuação das ONGs tem vagado com diferentes sentidos, desarticuladamente, no que se refere às condiçóes para realizar a educaçáo como direito: o fortalecimento tanto do Estado quanto da sociedade civil, a interlocução entre estes polos e a influência recíproca entre educação e sistema político.

Palavras-chave: ONG; direito à educação; política educacional.

\section{The NGOs and governmental responsibility for basic school in Brazil}

Abstract: This paper presents some of the NGOs' main meanings in Brazil that enable them to face the challenge of having the right to education. . This challenge particularly includes public schooling and the definition of public and private sector. In both aspects the following perspectives adopted by the NGOs are described: the palliative perspective, the innovative one, the changing as well as the political pressure perspective. The article concludes that the NGOs' work has been following different directions, disjointedly, in what concerns the conditions for accomplishing education as a right: strengthening both the State and the civil society, the interlocution between these two poles and the reciprocal influence between education and political system.

Key words: NGO; right to education; educational policy.

As denominadas ONGs se multiplicaram muito nos últimos 20 anos e passaram a desempenhar um papel mais importante e mais visível no campo educacional brasileiro. Esta atuação expressa o seu potencial tanto para conservar quanto para superar alguns traços característicos de nossas práticas educacionais. Este artigo apresenta alguns dos principais significados que as ONGs assumiram no Brasil, os

* Professor da Faculdade de Educação da Universidade de São Paulo (FE/NSP), Brasil. elie@usp.br 
quais as posicionam diante do desafio do direito à educação. Desafio que abarca, especialmente, a escolarizaçáo pública e a definição do campo público e do privado, nas quais as ONGs seguem a perspectiva paliativa, a inovadora, a de mudança ou a de pressão política.

\section{ONGs e seus significados no Brasil}

O caráter não-governamental das ONGs as situa como organizaçôes da sociedade civil. Sociedade civil e Estado sáo conceitos que derivam da grande dicotomia dada pela dupla privado e público. Entretanto, assim como o Estado se enraizou na sociedade, sobretudo por meio da regulação das relaçóes econômicas, também houve um processo inverso por várias formas de participaçáo nas opçóes políticas e de crescimento das organizaçôes de massa que exercem direta ou indiretamente algum poder político (Bobbio, 1997, p. 51).

Para muitos usos, é apropriado chamar de organizaçóes não-governamentais aquelas sem fins de lucro. Algumas se constituíram como associações a partir de um grupo social que, frente a seus oponentes, visou defender seus próprios interesses. É o caso dos sindicatos, que procuram congregar a maior parte de cada categoria de trabalhadores, podendo ser considerados associações de massa. Muitas outras associaçóes definidas pelo trabalho se formaram, mas, em torno do prestígio, da confiabilidade, da preservação e do desenvolvimento de um saber profissional, a exemplo das associaçôes técnicas e científicas ou de profissionais liberais. Outras se compuseram por praticantes ou pessoas que apreciam certos objetos ou atividades, tais como as artísticas e as esportivas.

Pelo menos desde o século XIX, organizaçóes não-governamentais sem fins de lucro surgiram com motivaçôes religiosas, políticas, ou ambas, para defender interesses de outros grupos. Frequentemente, isto ocorria porque estes náo mostravam ter condiçôes de se defender sozinhos: escravos; crianças; mulheres; povos indígenas; pessoas idosas, desempregadas, deficientes, aditas ao álcool ou com outras doenças mentais e físicas; imigrantes; famílias deslocadas por guerras, não alfabetizadas; pequenos camponeses arruinados; detentos, etc. As ONGs, na grande maioria, não podem ser consideradas associaçóes de massa, pois poucas filiam milhares de pessoas, como ocorre com o Greenpeace, que abarca interesses não identificados a um ou a limitados e específicos grupos sociais.

Há também uma grande divisão, difícil de estabelecer na prática. Na defesa de um grupo social vulnerável, as ONGs podem ser indiferentes à capacidade de este grupo passar a atuar autonomamente, ou podem, mesmo, proceder de modo a mantê-lo em sua vulnerabilidade, embora o ajudem. Este caminho é característico da chamada filantropia ou, como veio sendo denominado, do assistencialismo. Mas as ONGs podem também orientar-se por criar condiçóes para que um grupo que 
não consegue se expressar por si e agir em sua própria defesa passe a se fortalecer e atuar com autonomia, afirmando seus próprios interesses e tomando decisóes.

Oliveira e Haddad (2001) ressalvam que, na América Latina, ONGs são consideradas uma classe especial de organizaçóes dedicadas ao "desenvolvimento participativo e sustentável e à construção e defesa de direitos" e "não se confundem com entidades comunitárias e de auto-ajuda, com centros de pesquisa, fundaçóes e entidades filantrópicas de corte tradicional" (Oliveira; Haddad, 2001, p. 63). De todo modo, a atividade das ONGs comporta muito de educacional e, de certo ponto de vista, toda a sua atividade é educacional. Neste sentido, as ONGs estão educando quando fazem denúncias de exploraçáo do trabalho infantil, mobilizam para manifestaçôes contra o pagamento da dívida pública, distribuem informações sobre doenças sexualmente transmissíveis, debatem a proteção às mulheres pela previdência social, articulam segmentos em torno da urbanizaçáo de favelas, assessoram iniciativas de agricultura familiar, organizam campanhas pela zona semiárida do Nordeste brasileiro, etc.

Muitas ONGs também atuam em áreas amplamente reconhecidas como educacionais. Há aquelas que se classificam como educação informal, que envolvem a recreação, o esporte ou o uso de meios eletrônicos de comunicação, por exemplo. Outras são de tipo não-formal e tendem a se assimilar a práticas escolares sem incluir o controle e a certificação do Estado. Outras áreas educacionais são tipicamente formais, porque são escolas de educação básica, mantidas ou diretamente operadas por ONGs, ou porque sáo projetos cujas atividades se referem ao mundo escolar, em escolas particulares ou geridas pelo poder público.

O envolvimento das ONGs com educação no Brasil já tem décadas. Nos anos 1960 e 1970, grupos de pessoas oriundas de igrejas, partidos políticos ou universidades criaram associaçóes civis sem fins lucrativos, dedicadas ao chamado trabalho social com os segmentos mais empobrecidos (Fernandes, 1994, p. 23). Estavam empenhadas na crítica à sociedade durante a ditadura militar, na compreensão, pelos segmentos desfavorecidos, das causas de suas condiçôes de vida, realizando educação popular na defesa dos direitos humanos. A Igreja Católica foi um grande campo em que transcorreram tais atividades, no movimento das milhares de Comunidades Eclesiais de Base que se formaram (Singer; Brant, 1980).

O caráter fragmentário e marginal daquele trabalho, a censura e a repressão do regime militar somavam-se na dissociaçáo entre seus processos educativos e os sistemas escolares públicos. Além disto, as teorias críticas estavam concentradas em conferir às escolas um caráter essencial de reprodutoras de ideologias dominantes e de relaçóes de classe, voltadas a reforçar o capitalismo, as desigualdades sociais e a pobreza.

O esgotamento do regime militar e a abertura do sistema político coincidiram com a multiplicação de movimentos populares de reivindicaçáo por terra rural ou 
urbana ou por salários, com o revigoramento de sindicatos e constituição de centrais sindicais; e também com a expressão de uma grande diversidade de categorias e aspectos da vida social, muitas vezes remetendo a dimensôes também culturais, entre as quais as de relaçóes de gênero e entre etnias (sobretudo entre contingentes negros e não-negros). Algumas $\mathrm{ONGs} \mathrm{passaram} \mathrm{a} \mathrm{prestar} \mathrm{assessoria} \mathrm{a} \mathrm{órgãos}$ públicos e a se envolver em lutas para ampliar o acesso à escolarização pública e a qualidade da educação escolar para as camadas populares.

A acentuada dependência da economia brasileira quanto às oscilaçóes do capital financeiro internacional, cultivada nos anos 1980 e 1990, aliou-se às orientaçóes que predominaram na reforma do Estado, retirando as bases para a realização dos direitos expressos na Constituição, inclusive do direito à educação. A noção de espaço público se nublou, governos passaram a convocar a participação da sociedade civil, nomeadamente as ONGs, nos serviços públicos. Isto ocorreu em um período de mais reconhecimento das demandas e de fortes restriçóes de recursos, favorecendo também a simples substituição do Estado por organizaçóes civis na prestação dos serviços. Aumentou, portanto, o risco de escolhas pouco criteriosas, de mau uso dos recursos disponíveis e de abandono da meta de abrangência universal dos serviços.

Organizações da sociedade civil oferecem diretamente serviços educacionais mediante convênios e terceirização ou substituem funçôes técnicas de órgãos públicos na formação de pessoal, na elaboração de materiais de estudo e na formulação de orientaçóes pedagógicas. Ao mesmo tempo, ONGs com propósitos sedimentados na promoção dos direitos humanos e da democracia procuraram contribuir para o redirecionamento e o fortalecimento da atuaçáo do Estado em educaçáo. Contudo, quer educando, quer influindo em outras práticas educacionais, o caráter privado das ONGs as coloca no centro de um desafio: a realização do direito à educação. Desafio que remete imediatamente às escolas públicas.

\section{ONGs e escolas}

A atuação das ONGs em educação escolar pode ser considerada a partir das perspectivas: paliativa, inovadora, de mudança ou de pressão política. $\mathrm{O}$ caráter paliativo do trabalho das ONGs se verifica quando mantêm serviços escolares ou quando se constituem como estabelecimentos escolares. Nesta linha, remedeiam provisoriamente as lacunas do poder público na garantia do direito à educação em sua expressão escolar.

$\mathrm{Na}$ perspectiva inovadora, as ONGs questionam práticas ineficientes com experimentos de alternativas às realidades que criticam. Tais experimentos servem de inspiração a outros grupos e de fundamento para programas governamentais. $\mathrm{O}$ impacto desta atuação varia conforme o êxito em estabelecer novos programas 
públicos ou em obter apoio do Estado para implementar programas próprios em maior escala.

Na perspectiva de mudança, as ONGs podem atuar para fazer convergir práticas orientadas pela lógica de inovação com outras orientadas pela lógica de reforma educacional. As primeiras são iniciativas isoladas, de baixa visibilidade e escassa sustentabilidade no tempo, devido à limitação de recursos alocados em projetos, às condições extraordinárias de realização e, muitas vezes, à falta de sistematização. Por sua vez, as práticas reformadoras incluem grande abrangência, alta visibilidade, sustentabilidade decorrente de recursos orçamentários para programas oficiais e caráter homogêneo para numerosos estabelecimentos escolares distribuídos em amplos territórios. A convergência das práticas inovadoras com as reformadoras é rara, o que confere baixo impacto à perspectiva de mudança até o momento.

A perspectiva da pressão política se distancia das práticas educacionais diretas e se concentra nas condiçóes gerais de recursos para aquelas práticas outras, cujo suprimento depende de prescriçôes legais e de seu cumprimento.

\section{I. A perspectiva paliativa}

As lacunas existentes na atuação do Estado em relação ao direito à educação em sua expressão escolar são grandes e de variados tipos. A Constituição da República, em seu artigo 205, estabelece literalmente: "a educação, direito de todos, dever da família e do Estado [...]” (Brasil, 1988). Porém, em 2004, no Brasil, de 60.086.341 pessoas com idade entre 0 e 17 anos, 15.750 .821 não frequentavam creche ou escola (Brasil, 2004). Em 2005, 8,8\% das pessoas com idade entre 5 e 17 anos náo frequentavam escola, índice que chegou a $12 \%$ na regiáo norte (Brasil, 2005). No mesmo ano, $80,8 \%$ das pessoas com 5 anos ou mais de idade que frequentavam escola o faziam em estabelecimentos públicos, sendo que apenas $76,3 \%$ daquelas com idade inferior estavam neste tipo de estabelecimento.

Houve uma gradativa elevação do nível de escolarização, sinalizada pela queda dos índices de analfabetismo e pelo aumento da proporção de pessoas com 10 anos ou mais de idade que atingiram pelo menos 11 anos de estudo. Mas as atividades escolares também concorrem com o trabalho e, entre 2004 e 2005, passou de $11,8 \%$ para $12,2 \%$ (5,1 milhóes de pessoas) o grupo de pessoas entre 5 e 17 anos de idade que trabalhavam (Fórum, 2007). Das 33.282.663 matrículas no Ensino Fundamental, em 2006, 1.394.746 eram no período noturno.

A atuação paliativa de ONGs na educação escolar incide propriamente nos déficits de cobertura dos serviços escolares públicos, uma vez que grupos de extensas áreas rurais ou de periferias urbanas não contam com quantidade suficiente de estabelecimentos.

A educação profissional no Ensino Básico cresceu 14,5\% entre 2002 e 2003 (675 mil matrículas), tendo aumentado 1\% no Ensino Médio. As escolas par- 
ticulares tiveram um crescimento de 20,8\% (393 mil matrículas em 2003), contra um aumento de $6,7 \%$ na rede pública (282 mil). Diante da demanda por educaçáo profissional, em outubro de 2004, o governo federal lançou o projeto Escola de Fábrica "para estimular empresas e o terceiro setor a investir no ensino técnico" (Strauss, 2004). O Ministério da Educação informou que seria necessário praticamente quadruplicar o número de vagas no ensino profissional para obter 2 milhóes de pessoas treinadas que o mercado de trabalho exige (Strauss, 2004). O projeto abrangia só 10 mil estudantes, salas de aula montadas por empresas, execução "realizada por entidades do terceiro setor", com programação cabendo aos Centros Federais de Educação Tecnológica (Cefets).

A eficácia momentânea do trabalho de ONGs, complementando e ou substituindo a açáo do Estado, pode acudir exemplarmente alguns casos, mas, sempre poucos, diante da larga escala de pessoas cujos direitos universais são desrespeitados. É também o caso daquelas com deficiência e das que estão em posição de desvantagem na disputa acirrada por vagas em educaçáo superior. Um exemplo antigo de atuação paliativa de ONGs é a Campanha Nacional de Escolas da Comunidade (CNEC), fundada em 1943. Chegou a manter mais de 2 mil unidades, "estabelecendo-se principalmente junto àquelas comunidades em que o Estado não apresentava condiçôes de suprir as carências" (CNEC, 2007) e a ter 454.793 estudantes em 1984, ano em que contou com mais matrículas desde sua criação.

Quanto à educação especial, há raros estudos sobre sua participação nas despesas públicas (Gomes; Amaral Sobrinho, 1996, p. 25). Mas a compra de vagas em estabelecimentos privados é um mecanismo considerado comum, que permite a transferência de "quantidades substanciais da receita pública para escolas particulares" (Gomes; Verhine, 1996, p. 205). Nos estados menos desenvolvidos, o poder público terceiriza serviços com subvençôes a ONGs e, nos mais desenvolvidos, a subvenção a ONGs se concentra na atenção a pessoas com necessidades especiais mais severas, enquanto as demais são recebidas nas escolas públicas, numa política mais integracionista.

Em Educação Infantil, qual é a exata dimensão dos serviços prestados por ONGs? Os dados disponíveis não permitem responder adequadamente. Entre 2001 e 2003, o crescimento médio anual de matrículas foi de $6,4 \%$ em creches e de 3,5\% na pré-escola (Brasil [2004], p. 4);35\% das pessoas que trabalhavam na pré-escola tinham curso superior (Luz, 2006, p. 10). O crescimento das matrículas entre 1970 e 1985 havia sido de 991,8\%, com o aumento do número de docentes com formação inferior ao nível do Ensino Médio (Rosemberg, 2002, p. 10). Durante os anos 1990, a influência do Banco Mundial nas políticas educacionais fez retornar aos "velhos modelos 'não formais', a 'baixo custo', através da 'participação da comunidade"” (Drewinski, 2001, p. 125), tempo em que os governos estaduais abandonaram as pré-escolas, pois ofertavam $23,4 \%$ das matrículas em 
1996 e, em 2003, este número passou a 7,9\% (Abreu, 2004, p. 10). Os recursos federais às creches filantrópicas, assistenciais e comunitárias se extinguiram, e estas ficaram na dependência apenas dos governos municipais ou da cobrança de baixas mensalidades, com profissionais não especializados e funcionamento em locais não apropriados (Arelaro, 1999, p. 31), processo que foi criticado como um desengajamento do Estado, indutor de privatização (Leão, 1999, p. 117). As creches geralmente ficaram voltadas para as famílias mais pobres, em condiçóes precárias e sem programação pedagógica (Campos, 2006; Pacheco; Meler; Teixeira, 2004).

Os gastos do Brasil em educação pré-escolar são semelhantes aos dos países da Organização para a Cooperação e o Desenvolvimento Econômico (OCDE), ou seja, da ordem de $0,4 \%$ do PIB. Porém, a taxa média de matrícula de crianças de 3 a 4 anos na Educação Infantil, em países da OCDE, é de 63,8\% e, no Brasil, é de 26,6\% (Choi, 2004, p. 27). A Constituição permite destinar recursos públicos para escolas comunitárias, confessionais e filantrópicas (definidas no artigo 77 da LDB), que comprovem finalidade não lucrativa, apliquem seus excedentes em educação e assegurem que seu patrimônio seja transferido a outra escola da mesma natureza, quando se encerrem suas atividades (Brasil, 1988, art. 213, I e II). Mas há disputas, porque a possibilidade de financiamento daquelas escolas apenas ocorre em caso de falta de vagas nas redes públicas (Martins, 2002, p. 3).

A presença do Estado na oferta de educação escolar básica é majoritária e muito significativa, porém, os déficits são também de grandes dimensóes. Devem-se reconhecer os benefícios que esforços de serviços não-governamentais propiciam, já que a sua oferta imediata significa, muitas vezes, a única possibilidade de escolarização. Mas, mesmo a lei prevendo este auxílio apenas em caráter emergencial e provisório, este tem sido alternativa duradoura, tendente a efeitos negativos, pois, se a cobertura por ONGs complementa a oferta estatal, não o faz exaustivamente, e os grandes déficits que permanecem mostram a acomodação à omissão do Estado.

Tal acomodação implica abandonar a meta de cobertura universal (ou suficiente), buscá-la por meio da ampliação dos serviços de ONGs ou pelas empresas escolares e, neste último caso, mediante o pagamento pelas pessoas beneficiárias. Opção injusta e contraditória com as obrigaçôes do Estado fixadas na Constituição.

\subsection{A perspectiva inovadora}

Nem sempre em âmbito escolar, as ONGs de perspectiva inovadora experimentam atividades educacionais pouco frequentes no trabalho comum de outras ONGs e de escolas. Em educação ambiental, por exemplo, Carvalho (2003) assinala importante função desempenhada por ONGs no Brasil, embora note uma tendência a trabalhos isolados, sem interação nem cooperação entre governos, empresas, universidades e ONGs, de modo que interessantes experiências não são utilizadas por outras. 
Um exemplo é a ONG 4 Cantos do Mundo (2007), que visa promover açóes transformadoras por meio da educaçáo ambiental, da participação política e da pesquisa e aplicação de tecnologias que contribuam para o fortalecimento da cultura da paz e para a construção de sociedades sustentáveis. Um de seus projetos, iniciado em 2006 com a produção de material e visitas de diagnóstico, é desenvolvido com cinco escolas municipais de Belo Horizonte e a Secretaria Municipal de Educação, por meio de convênio com o Fundo Nacional de Desenvolvimento da Educação, do MEC. Assim como outras organizaçóes ambientalistas, compartilha da força mobilizadora de jovens no Grupo de Trabalho de Juventude, no âmbito do Fórum Brasileiro de ONGs e Movimentos Sociais pelo Meio Ambiente e Desenvolvimento. A ONG anima o Coletivo Jovem de Meio Ambiente de Minas Gerais (CJ), que é informal e autônomo.

Outra área de notável atuação educacional diz respeito à epidemia de Aids. Nos anos 1980, o surgimento de ONGs de combate à Aids voltou-se a um conjunto de açôes para o enfrentamento da doença, no qual a educação teve lugar central. Em torno da epidemia, havia-se estabelecido a divisão entre pessoas já infectadas como "vítimas-culpadas" e "vítimas-inocentes", indicando algumas com maior probabilidade de contrair o vírus, responsabilizando-as pela expansão da doença. Grupos que já eram discriminados - homossexuais, prostitutas, usuários de drogas injetáveis - tornaram-se alvos da acusação. Paralelamente, os governos não atuavam contra os perigos reais da epidemia, atrasando açóes globais que pudessem impedir a sua expansão. As ONGs conduziram alternativas consideradas positivas no controle da epidemia por setores médicos, leigos e religiosos. Reafirmaram que a vida sexual poderia manter-se juntamente com medidas baseadas na observância ao conhecimento científico disponível (Góis, 2007).

Algumas ONGs, com diferentes focos de interesse, foram fundadas em outros países e passaram a atuar em vários, inclusive no Brasil. Uma destas é o Children's International Summer Villages (Cisv), cuja sede internacional fica na Inglaterra. O Cisv se apresenta como uma organização independente, voluntária, apolítica e não-religiosa que promove a educação para a paz e a amizade intercultural. Criado há cerca de 50 anos, está em 65 países, formando líderes para a cooperação, a integração intercultural e a solução pacífica de conflitos. A organização conta com 150 seçóes no mundo, e uma das maiores é a de São Paulo. Sua proposta educacional se faz por meio de programas de convivência entre jovens de 11 a 18 anos, de diferentes países e culturas, com a finalidade de desfazer os preconceitos e mostrar alternativas construtivas de relacionamento com a intolerância e com o confronto (Cisv, 2007).

Um grupo com intençóes semelhantes, da região metropolitana de Porto Alegre, RS, engajou-se na paz através da educação e, em 2002, constituiu a ONG Educadores para a Paz. Seus projetos contemplam a capacitação de educadores das 
instituiçóes públicas e privadas por meio de curso, assessoria a escolas, publicação de subsídios e promoção de espaços de debate. Um dos projetos em escola pública de Cuiabá, MT, tem o objetivo de levar estudantes a refletir criticamente sobre esportes competitivos e vivenciar formas de jogo baseadas mais na cooperação (Educadores para a paz, 2000).

Outro aspecto inovador na linha de educação informal que cabe ressaltar passou a ser conhecido como educomunicação, que ONGs estimulam marcadamente quanto à participação ativa e à abordagem de assuntos condizentes com realidades locais (Peruzzo, 2006). A ONG Escola Brasil, por exemplo, utiliza o rádio como instrumento de mobilizaçáo social, atuando como porta-voz de comunidades da zona rural, cidades do interior do Brasil e periferias de grandes capitais, na luta pela garantia do direito constitucional à educação. A ONG capacita também profissionais do rádio e divulga leis sobre direitos das crianças, adolescentes e populaçôes de baixa renda (Escola Brasil, 2007).

\subsection{A perspectiva de mudança}

O programa Melhoria da Educação no Município, com apoio da Fundação Itaú Social, é uma iniciativa que se encaminha na perspectiva da mudança educacional, uma vez que sua realização aproxima práticas originadas em uma lógica de reforma de outras surgidas na lógica de inovação. Foi criado em 1999 e incentiva alianças de autoridades e técnicos dos órgãos públicos com profissionais que trabalham educando diretamente e com líderes de associações locais. É de responsabilidade conjunta da ONG Centro de Estudos e Pesquisas em Educação, Cultura e Ação Comunitária (Cenpec), do Unicef e da União Nacional dos Dirigentes Municipais de Educação (Undime) e visa a envolver, assessorar e fortalecer equipes governamentais e não-governamentais. Iniciou no estado de São Paulo, com 600 educadores(as) de 176 municípios, agrupados em 13 polos. A orientação colocada a cada um destes foi desenvolver parcerias e envolver as cidades de suas regiốes em uma rede de ações (Fundação Itaú Social, 2007). Propôs-se "identificar e motivar as lideranças educativas" (Fundação Itaú Social, 2007), de modo a planejar e desenvolver projetos educacionais durante todo o ano letivo.

Outra iniciativa da Fundação Itaú Social em conjunto com o Unicef é o programa Educação e Participação. Volta-se para "o sucesso escolar", "o desenvolvimento integral de crianças e adolescentes" e apoia açóes "que favoreçam a educação como um todo" para a permanência e o sucesso de crianças e jovens no sistema público de ensino: a construção de uma ponte entre escolas e ONGs, a mobilização da sociedade brasileira para a geração e multiplicação de iniciativas semelhantes, o fortalecimento da proteção social e educação, o debate e a formulação de políticas públicas para a infância e a adolescência (Fundação Itaú Social, 2007). O programa se compóe com o Prêmio Itaú-Unicef, Encontros Regionais de Formação 
e o projeto Gestores de Aprendizagem (Fundação Itaú Social, 2007). O Prêmio apoia financeiramente as ONGs que atuam em favor da escola pública, tendo em vista "o ingresso, regresso, permanência e sucesso na escola pública de crianças e jovens de baixa renda” (Fundação Itaú Social, 2007). Focaliza organizaçóes sem fins lucrativos (associaçóes e movimentos comunitários, sindicatos, pactos pela educação e similares), que dependem de outras fontes de recursos, e que trabalhem com pessoas de baixa renda e idade de 7 a 18 anos. Em 2003, chegou a receber 1.834 inscrições de todos os estados brasileiros.

A atuação das ONGs em escolas públicas de educação básica mostra oscilações entre açóes marginais (com propostas próprias e isoladas) e açóes de colaboração com profissionais de estabelecimentos e redes escolares. Há aproximaçóes entre ONGs, magistério, corpos técnicos, sindicatos e órgãos administrativos, mas ainda predomina o distanciamento entre estes campos. Há casos de operação paralela à escola, caracterizando-se como uma proposta formativa autônoma, sem intenção de intervir diretamente no sistema escolar, reduzindo-se a visitar escolas para ter contato com jovens, o que é feito também em igrejas, partidos políticos, centros de formação profissional, clubes, etc. (Brunstein, 2003).

Outro tipo de proposta procura melhorar ou transformar a escola pública, apresentando alternativas de ação conjunta. Mas pode-se dizer que açôes de colaboração entre ONGs e escolas públicas são muito escassas. O projeto Integrar pela Educação é um exemplo deste tipo de açóes, provocado pela Fundação W. K. Kellogg, que lançou a iniciativa em educação básica Comunidade de Aprendizagem. Entre 1999 e 2002, as atividades do projeto se concentraram em escolas públicas e centros educativos comunitários da Zona Leste do município de São Paulo. As características de pobreza das áreas onde atuou o projeto agravam traços gerais da educação escolar, a qual o projeto entendeu vir perdendo sentido, por não responder a necessidades econômicas, políticas e culturais das populaçóes. O principal objetivo do projeto, coordenado por uma equipe composta por uma pessoa de cada organização responsável: uma escola municipal de Ensino Fundamental, uma estadual de Ensino Médio, três grupos informais e duas ONGs (Giglio, Ghanem; Madeira, 2004, p. 179), foi gerar novos sentidos para esta educação, combinando práticas escolares e não escolares.

O projeto atuou deliberadamente para aperfeiçoar a dimensáo de aprendizagem de diferentes comunidades do seu ambiente. A fim de gerar novos sentidos para a educação escolar, trabalhou para: aumentar a influência de alunos e familiares na orientação da educação escolar; fortalecer o fórum aberto de debates sobre educação como interlocutor coletivo nas políticas educacionais governamentais; recompor relaçóes interpessoais e intergrupais por meio de práticas educacionais artísticas e associativas; manter relação ativa com os meios de comunicação de massa (Ghanem, 2007). 


\subsection{A pressão política}

Além das variadas formas de relacionamento das ONGs com práticas escolares, sua grande contribuição ao direito à educação tem sido a atuação direta no sistema político. São organismos internacionais, governos e ONGs os principais envolvidos em políticas públicas, geralmente operando com uma noção de sociedade civil limitada a ONGs, embora estas sejam apenas um tipo de organizaçóes da sociedade civil. Não obstante predomine esta visão limitada, no Brasil, algumas ONGs têm-se sobressaído na defesa de que a participação seja muito mais ampla e variada. O exemplo que sintetiza este esforço é o da Campanha Nacional pelo Direito à Educação, lançada no contexto da preparação da Cúpula Mundial de Educação em Dacar, ano 2000. A missão a que a Campanha se propôs foi contribuir para a efetivação dos "direitos educacionais garantidos na Constituição, por meio de ampla mobilização social, de forma a que todos tenham acesso a uma escola pública de qualidade" (Campanha, 2007).

O principal desafio delineado pela Campanha é a qualidade da educação pública, e, em consequência, sua atuação está direcionada a disseminar largamente o conceito de educação enquanto direito humano fundamental, focalizando o aumento do financiamento para a educação pública; a valorização do magistério; e a ampliação dos processos participativos em educação. $\mathrm{Na}$ ocasião de seu lançamento, o Comitê Diretivo da Campanha estava composto pelas ONGs Ação Educativa (São Paulo, SP), Centro de Cultura Luiz Freire (Olinda, PE), Centro de Criação e Imagem Popular - Cecip (Rio de Janeiro, RJ), Instituto Brasileiro de Análises Sociais e Econômicas - Ibase (Rio de Janeiro, RJ); pelo Fórum Nacional da Juventude; pela Confederação Nacional dos Trabalhadores em Educação - CNTE; e pela ONG britânica ActionAid. Em 2008, a Campanha já congregava cerca de 120 organizaçóes de todo o Brasil, incluindo ONGs nacionais e internacionais, sindicatos, universidades, secretárias e secretários de educação e organizaçóes estudantis e juvenis. Comitês estaduais estavam estruturados em 13 estados e, no conjunto, a Campanha contava com apoio financeiro de três organizaçóes britânicas (ActionAid, Oxfam Internacional e Plan) e uma holandesa (Novib).

A Campanha promoveu a mobilização contra os vetos à lei do Plano Nacional de Educação (PNE), Lei n. 10.172, que, aprovada em 9 de janeiro de 2001, orientava por dez anos as açóes da União, dos estados e dos municípios. Foi sancionada com vetos do presidente Fernando Henrique Cardoso, relacionados à ampliação de recursos para a educação, retirando a garantia de meios para realizar o plano. $\mathrm{O}$ investimento em educação era estimado em cerca de 4,6\% do Produto Interno Bruto (PIB), e a lei previa o aumento progressivo para $7 \%$, o que significaria um acréscimo de 24 bilhóes de reais.

Em novembro de 2007, a Campanha publicou o livro Custo aluno-qualidade inicial, baseado em amplo estudo realizado por sua rede durante quatro anos. Em 
suma, calculou aquele custo (CAQi), especificando recursos e insumos mínimos (Carreira; Pinto, 2007). Nesta perspectiva, operou-se uma inversão importante da tradição pela qual não são as necessidades que orientam a destinação de recursos financeiros, mas, ao contrário, supondo um montante mais ou menos disponível de recursos, este é dividido pelos itens de despesa que se costuma fazer.

Já em outubro de 2007, a Campanha recebeu do Congresso Nacional o prêmio Darcy Ribeiro por sua bem-sucedida atuação no processo de criação e aprovação do Fundo da Educação Básica (Fundeb). A proposta deste fundo, em substituição ao Fundef (restrito ao nível de Ensino Fundamental), começou a ser oficialmente considerada pelo MEC em 2004. A Campanha sugerira ao MEC a criaçáo de um grupo de mediação para tratar do tema; o grupo foi criado e a Campanha também fez parte dele. Em meados de 2005, o Poder Executivo apresentou a proposta de emenda à Constituição que criava o Fundeb, e a Campanha passou a acompanhar intensamente a tramitaçáo legislativa da matéria. Coordenou o vitorioso movimento "Fundeb pra Valer!", articulando grupos de ativistas e pesquisadores da área educacional, organizaçóes sindicais, empresariais, feministas e populares, parlamentares, conselhos sociais, etc. Entre as conquistas, o Fundeb passou a abarcar também as creches.

\section{Conclusão}

É indispensável a advertência de que fixar para as ONGs apenas uma característica, não ter fins lucrativos, mantém a confusão da multiplicidade de propósitos que podem assumir (Oliveira; Haddad, 2001, p. 63). Confusão agravada pelo difundido uso da expressão "terceiro setor", uma suposta interseção entre o espaço público e o privado que reuniria virtudes de ambos. Se as ONGs passaram por crescente aumento de importância e visibilidade, acompanhando processo semelhante do conjunto da sociedade civil, houve também a sua valorização ingênua, atribuindo-lhes responsabilidades e a realização de trabalhos que caberiam ao poder público. Assim, mesclam-se prestaçóes filantrópicas diretas a estratos desfavorecidos e colaboraçóes com escolas públicas. Entrelaçamentos pelos quais se sedimenta o terceiro setor, em arranjos incertos que não conferem plenitude e sustentabilidade ao direito à educação.

Realizar a educação como direito depende do fortalecimento tanto do Estado quanto da sociedade civil, assim como depende da interlocução entre estes polos e da influência recíproca entre educação e sistema político. A atuação das ONGs tem vagado com diferentes sentidos em cada um destes aspectos, desarticuladamente, algumas desfazendo o que outras fazem.

As ONGs são, contudo, somente pequena parcela de um grande e variado conjunto de organizaçôes da sociedade civil. O aproveitamento de sua participa- 
ção na transformação da educação praticada no Brasil decorrerá também do que fizerem pela mobilização ampla e pelo diálogo constante em torno da tomada de decisões sobre política educacional, desde as definições legais até as práticas diretas nos estabelecimentos educacionais.

\section{Referências bibliográficas}

4 CANTOS DO MUNDO. Disponível em: <http://www.4cantosdomundo.org.br/ projetos.html>. Acesso em: 10 ago. 2007.

ABREU, M. Educação infantil no Brasil: legislação, matrículas, financiamento e desafios. Brasília: Câmara dos Deputados, 2004. 18 p.

ARELARO, L. R. G. Financiamento e qualidade da educação brasileira: algumas reflexões sobre o documento "Balanço do primeiro ano do FUNDEF - Relatório MEC". In: DOURADO, I. F. Financiamento da educação básica. São Paulo: Autores Associados, 1999.

BOBBIO, N. Estado, governo, sociedade: para uma teoria geral da política. Traduçáo de Marco Aurélio Nogueira. Rio de Janeiro: Paz e Terra, 1997. 173 p.

BRASIL. Constituição da República Federativa do Brasil. 1988

BRASIL. Instituto Brasileiro de Geografia e Estatística. Suplemento Educação: PNAD 2004. [2004]. Disponível em: <ftp://ftp.ibge.gov.br/Trabalho_e_Rendimento/Pesquisa_ Nacional_por_Amostra_de_Domicilios_anual/2004/Suplemento_Educacao/Brasil/>. Acesso em: 25 ago. 2007.

BRASIL. Instituto Brasileiro de Geografia e Estatística. PNAD 2005. [2005]. Disponível em: <http://www.ibge.gov.br/home/estatistica/populacao/trabalhoerendimento/pnad2005/ sintese/tab1_1.pdf>. Acesso em: 25 ago. 2007.

BRUNSTEIN, J. ONGs e educação: novas possibilidades educativas? 2003. 241 p. Tese (Doutorado) - Faculdade de Educaçáo, Universidade de São Paulo, São Paulo.

CAMPANHA NACIONAL PELO DIREITO À EDUCAÇÃO. Disponível em: <http:// www.campanhaeducacao.org.br/>. Acesso em: 4 out. 2007.

CAMPOS, M. M. Educação infantil. Disponível em: <http://www.reescrevendoaeducacao. com.br/2006/pages.php?recid=35>. Acesso em: 4 out. 2007.

CARREIRA, D.; PINTO, J. M. R. Custo aluno-qualidade inicial: rumo à educação pública de qualidade no Brasil. Sáo Paulo: Campanha Nacional pelo Direito à Educação: Global, 2007. $128 \mathrm{p}$.

CARVALHO, C. A. As ONGs e a educação ambiental no Brasil. 2003. Disponível em: <http://www.techoje.com.br/ietec/techoje/techoje/meioambiente/2003/01/24/2003_01 _24_0014.2xt/-template_interna>. Acesso em: 18 ago. 2007.

CHOI, S-H. Financiamento da educação infantil: perspectiva internacional. In: COELHO, R. C.; BARRETO, A. R. (Org.). Financiamento da educação infantil: perspectivas em debate. Brasília: Unesco Brasil, 2004. p. 19-30 
CISV. CISV Annual Review 2007. Disponível em: <http://www.cisv.org.br/>. Acesso em: 10 ago. 2007.

CNEC. Quem somos. 2007. Disponível em: <http://www.cnec.br/portal/>. Acesso em: 5 out. 2007.

DREWINSKI, J. M. A. Educação infantil: o direito negado nas políticas educacionais. Guaracá, Guarapuava, PR, n. 17, p. 111-133, 2001.

EDUCADORES PARA A PAZ. 2000. Disponível em: <http://www.educapaz.org.br/ index.php?option=com_content\&task=view\&id=52\&Itemid=6>. Acesso em: 10 ago. 2007.

ESCOLA BRASIL. 2007. Disponível em: <http://www.escolabrasil.org.br/>. Acesso em: 18 ago. 2007.

FERNANDES, R. C. Privado porém público: o terceiro setor na América Latina. Rio de Janeiro: Relume-Dumará, 1994.

FÓRUM NACIONAL DE PREVENÇÃO E ERRADICAÇÃO DO TRABALHO INFANTIL. Apesar da queda, números sobre trabalho infantil preocupam. Informativo, n. 8. Disponível em: <http://www.fnpeti.org.br/informativo/informativo_08.htm>. Acesso em: 20 out. 2007.

FUNDAÇÃO ITAÚ SOCIAL. Gestores nota dez para o ensino público. Disponível em: $<$ http://www.fundacaoitausocial.org.br/prog_educacao/melhoedu.htm>. Acesso em: 18 ago. 2007.

GHANEM, E. Influir em políticas prestando serviços a órgãos públicos? In: GHANEM, E. Influir em políticas públicas e provocar mudanças sociais: experiências a partir da sociedade civil brasileira. São Paulo: Ashoka; Avina; Imprensa Oficial do Estado de São Paulo, 2007. p. $99-107$

GIGLIO, C. M.; GHANEM, E.; MADEIRA, V. L. S. Integrar por la educación. São Paulo. Brasil. In: NEIROTTI, N.; POGGI, M. Evaluación de proyectos de desarrollo educativo local: aprendiendo juntos en el proceso de autoevaluación. Buenos Aires: IIPE Unesco, 2004. p. 177-207.

GÓIS, J. B. H. As ONGs e a educação anti-Aids no Brasil: avaliando o passado e pensando no futuro. Disponível em: <http://www.depotz.net/readarticle.php?article_ $\mathrm{id}=839 \&$ rowstart $=0>$. Acesso em: 18 ago. 2007.

GOMES, C. A.; AMARAL SOBRINHO, J. Educação especial no Brasil: perfil do financiamento e das despesas. Brasília: MEC; SEESP; Unesco, 1996. 160 p.

GOMES, C. A.; VERHINE, R. E. O financiamento do ensino público no Brasil: uma perspectiva político-econômica. Caderno CRH, Salvador, n. 24-25, p. 193-220, jan./dez. 1996.

LEÃO, G. M. P. "Novas” estratégias da gestão privada da educação pública. In: OLIVEIRA, D. A.; DUARTE, M. R. T. (Org.). Política e trabalho na escola: administração dos sistemas públicos de educação básica. Belo Horizonte: Autêntica, 1999. 
LUZ, I. R. Educação infantil: direito reconhecido ou esquecido? Linhas Críticas - Revista da Faculdade de Educação, Brasília, v. 12, n. 22, p. 41-58, jan./jun. 2006.

MARTINS, P. S. O Fundefe as escolas comunitárias, filantrópicas, confessionais e de educação especial. Brasília: Câmara dos Deputados, 2002. 5 p.

OLIVEIRA, A. C.; HADDAD, S. Organizaçóes da sociedade civil e as ONGs de educação. Cadernos de Pesquisa, São Paulo, n. 112, p. 61-83, mar. 2001.

PACHECO, A. L. P. B.; MELER, A.; TEIXEIRA, C. G. M. Metodologia de avaliação: relato de uma experiência de pesquisa. In: COELHO, R. C.; BARRETO, A. R. (Org.). Financiamento da educação infantil: perspectivas em debate. Brasília: Unesco Brasil, 2004. p. $72-89$

PERUZZO, C. K. Comunicação comunitária e educação para a cidadania. 2006. In: SIMPÓSIO EM COMUNICAÇÃO DO CENTRO-OESTE, 5., 20 de maio de 1999, Faculdade de Educação da UFG, Goiânia. Disponível em: <http://www.educacionenvalores. org/article.php3?id_article=844>. Acesso em: 18 ago. 2007.

ROSEMBERG, F. Organizações multilaterais, estado e políticas de educação infantil. Cadernos de Pesquisa, São Paulo, n. 115, p. 25-63, mar. 2002.

SINGER, P.; BRANT, V. C. (Org.). São Paulo: o povo em movimento. Petrópolis: Vozes; São Paulo: Cebrap, 1980. 230 p.

STRAUSS, L. R. Governo tenta estimular empresas e Ongs a investir no ensino técnico. Folha de S. Paulo, São Paulo, 21 out. 2004. Cotidiano. Disponível em: <http://www.serpro. gov.br/noticiasSERPRO/20041021_04>. Acesso em: 18 ago. 2007.

Recebido em 05 de janeiro de 2012 e aprovado em 06 de março de 2012. 
